\begin{tabular}{|c|l|}
\hline Title & Biosorption of Heavy Metal Ions to A Marine Microalga, Heterosigma akashiwo (Hada) Hada \\
\hline Author(s) & Seki, Hideshi; Suzuki, A kira; Iburi, Y asuyuki \\
\hline Citation & $\begin{array}{l}\text { Journal of Colloid and Interface Science, 229(1), 196-198 } \\
\text { https://doi.org/10.1006/cis.2000.6998 }\end{array}$ \\
\hline Issue Date & 2000-09-01 \\
\hline Doc URL & http://hdl.handle.net/2115/44068 \\
\hline Type & article (author version) \\
\hline File Information & 2000.pdf \\
\hline
\end{tabular}

Instructions for use 


\title{
Biosorption of Heavy Metal Ions to A Marine Microalga, Heterosigma akashiwo (Hada) Hada
}

\author{
HIDESHI SEKI, AKIRA SUZUKI AND YASUYUKI IBURI
}

Division of Marine Biosciences, Graduate School of Fisheries Science, Hokkaido University,

Minato-cho 3-1-1 Hakodate 041-8611, Japan

(Abbreviated title: BIOSORPTION OF HEAVY METALS TO MARINE MICROALGA)

Hideshi Seki

Division of Marine Biosciences, Graduate School of Fisheries Science, Hokkaido University,

Minato-cho 3-1-1 Hakodate 041-8611, Japan

e-mail seki@elsie.fish.hokudai.ac.jp 


\begin{abstract}
A fundamental study of the application of marine microalga to the aqueousphase separation of toxic heavy metals was carried out. The biosorption characteristics of cadmium and lead ions were determined with marine microalga, Heterosigma akashiwo (Hada) Hada which was inactivated by steam sterilization. A simple metal-binding model was used for the description of metal binding data. The results showed that the biosorption of bivalent metal ions to $H$. akashiwo was due to monodentate binding to two different types of acidic sites: carboxylic and phosphatic-type sites.
\end{abstract}

Key Words: biosorption; heavy metal; marine microalga; Heterosigma akashiwo. 


\section{INTRODUCTION}

The concentration of toxic heavy metals in natural water is very low, however, they become concentrated throughout the food chain to the extent of posing a serious health hazard to humans $(1,2)$. The metal recovery from dilute solutions by biosorption is an emerging field of interest, from both a resource conservation standpoint and an environmental remediation standpoint. Since the biosorption process employs inexhaustible, inexpensive, and nonhazardous materials, it may be suitable for the environmental remediation process which needs the low-cost adsorbents. Thus microorganisms $(3,4)$, algae $(5,6)$, and other types of biomass have been investigated for use in this application.

In the present study, the biosorption characteristics of cadmium and lead ions in acidic media were investigated with a marine microalga, Heterosigma akashiwo (Hada) Hada. H. akashiwo is a major constituent of red tides on the coast of Japan. Red tides emerge suddenly in the eutrophied sea area and cause serious damages to the coastal fishery. Looking at this from another angle, red tide planktons are regarded as an inexhaustible and attractive material for the biosorbent. In this paper, the acid-dissociation characteristics of the acidic sites on $H$. akashiwo were determined from the results of potentiometric titration. 
Then the biosorption mechanism of lead and cadmium ions to H. akashiwo was discussed based on a simple metal-binding model (4). 


\section{MATERIALS AND METHODS}

\section{Materials}

Cadmium nitrate, lead nitrate and sodium nitrate were obtained from Wako Pure Chemical Industries (Japan). They were used as received. Heterosigma akashiwo (Hada) Hada was obtained from the laboratory of chemical oceanography, Hokkaido University, Japan. It was grown in a batch to the lateexponential growth stage in seawater medium. The cells were harvested, inactivated in an autoclave at $120^{\circ} \mathrm{C}$ for $15 \mathrm{~min}$, and washed three times with distilled water.

Potentiometric Titration of H. akashiwo

A suspension $\left(0.3 \mathrm{dm}^{3}\right)$ containing a certain amount of inactivated $H$. akashiwo and $\mathrm{NaNO}_{3}(0.1 \mathrm{~mol} \mathrm{dm}-3)$ was mechanically stirred at $30^{\circ} \mathrm{C}$. To eliminate $\mathrm{CO}_{2}, \mathrm{~N}_{2}$ gas was continuously bubbled through the system. After reaching thermal equilibrium, it was titrated with a volumetric standard solution of $\mathrm{HNO}_{3}$ or $\mathrm{NaOH}(0.1 \mathrm{~mol} \mathrm{dm}-3)$. The $\mathrm{pH}$ of the suspension was measured by a pH meter (Orion Research 720A). The number of protonated acidic groups of $H$. akashiwo was determined from the difference between the bulk proton concentrations in the presence of $H$. akashiwo and those in the absence of H. akashiwo. 
Biosorption Experiments

A solution of $\mathrm{NaNO}_{3}(0.1 \mathrm{~mol} \mathrm{dm}-3)$ containing a certain amount of $\mathrm{Cd}\left(\mathrm{NO}_{3}\right)_{2}$ or $\mathrm{Pb}\left(\mathrm{NO}_{3}\right)_{2}$ was prepared. The $\mathrm{pH}$ of the solution was adjusted to a desired value by $\mathrm{HNO}_{3}$. After reaching thermal equilibrium at $30^{\circ} \mathrm{C}$, a certain amount of inactivated $H$. akashiwo was added to the solution. The solution was stirred for a necessary time to attain the adsorption equilibrium, and then $H$. akashiwo was separated from the liquid phase in a centrifuge at 10,000 rpm for 20 min. The $\mathrm{pH}$ and metal concentration of the liquid phase were measured. The metal concentration was determined by an atomic absorption spectrophotometer (Hitachi A-1800). The amount of metal ion adsorbed to $H$. akashiwo was determined from the difference between the metal concentrations in the initial and the equilibrium states. 


\section{RESULTS AND DISCUSSION}

Acidc Sites on/in H. akashiwo

Figure 1 shows the protonation characteristics of acidic sites of $H$. akashiwo obtained from potentiometric titration. The ordinate of the figure, $X_{\mathrm{H}}$, represents the equilibrium number of protons bound to 1 dry-g of $H$. akashiwo. The acid-base property of bacteria was attributed to three different types of acidic sites: carboxylic, phosphatic, and amino groups $(4,7)$. Assuming that the similar relation holds in the present microalga, the acid-dissociation reactions of $H$. akashiwo can be written as

$$
\begin{aligned}
& -\mathrm{S}_{1} \mathrm{H} \leftrightarrow-\mathrm{S}_{1}^{-}+\mathrm{H}^{+} \quad ; K_{1} \\
& -\mathrm{S}_{2} \mathrm{H} \leftrightarrow-\mathrm{S}_{2}^{-}+\mathrm{H}^{+} \quad ; K_{2} \\
& -\mathrm{S}_{3} \mathrm{H}^{+} \leftrightarrow-\mathrm{S}_{3}+\mathrm{H}^{+} \quad ; K_{3} .
\end{aligned}
$$

$-\mathrm{S}_{1},-\mathrm{S}_{2}$, and $-\mathrm{S}_{3}$ represent the carboxylic, phosphatic, and amino-type sites of H. akashiwo, respectively. The acid-dissociation constant $K_{i}$ is defined as

$$
K_{i}=\alpha_{i}\left[\mathrm{H}^{+}\right] /\left(1-\alpha_{i}\right) \quad(i=1,2 \text {, or } 3),
$$


where $\alpha_{i}$ is the degree of dissociation of type $i$ acidic sites. The number of protons bound to 1 dry-g of $H$. akashiwo, $X_{\mathrm{H}}$, can be expressed as the sum of the number of protons bound to three types of acidic sites;

$$
X_{\mathrm{H}}=N_{1}\left[\mathrm{H}^{+}\right] /\left(K_{1}+\left[\mathrm{H}^{+}\right]\right)+N_{2}\left[\mathrm{H}^{+}\right] /\left(K_{2}+\left[\mathrm{H}^{+}\right]\right)+N_{3}\left[\mathrm{H}^{+}\right] /\left(K_{3}+\left[\mathrm{H}^{+}\right]\right)
$$

where $N_{1}, N_{2}$, and $N_{3}$ are the number of carboxylic, phosphatic, and amino groups on/in 1 dry-g of $H$. akashiwo, respectively. A nonlinear least-squares method was applied to find six constants, $K_{i}$ and $N_{i}$, in Eq. [5]. The constants, which gave the best fit with the experimental data (in Fig.1), are listed in Table 1. The solid line in Fig.1 represents the theoretical curve calculated from Eq. [5] using the constants listed in Table 1 . The correlation coefficient between the experimental and the predicted value was 1.00 .

Biosorption of Cadmium and Lead Ions to H. akashiwo

Plette et al. (3) investigated the binding of bivalent metal ions to the isolated cell walls of Rhodococcus erythropolis A177. They proposed a multicomponent competitive binding model based on the NICA (non-ideal competitive adsorption) model. The model gave good results for the description of metal ion binding data. The results showed that the biosorption 
of bivalent metal ions to the cell wall materials was due to monodentate binding to two different types of acidic sites: carboxylic-type sites (type 1) and phosphatic-type sites (type 2).

We applied a simplified version of the metal binding model proposed by Plette et al. to the biosorption of cadmium and lead ions to two bacteria; Alcaligenes eutrophus H16 and Rhodobacter sphaeroides. The result showed that the simplified model successfully explained the biosorption of bivalent metal ions to whole cell bodies of bacteria (4).

Assuming that the similar relation holds in the present microalga, the metal-binding reactions of the type 1 and type 2 sites on/in $H$. akashiwo can be written as

$$
-\mathrm{S}_{i}^{-}+\mathrm{M}^{2+} \leftrightarrow-\mathrm{S}_{i} \mathrm{M}^{+} \quad ; K_{\mathrm{Mi}} \quad(i=1 \text { or } 2) .
$$

Plette et al. selected the NICA model, that can account for both ion-specific nonideality and heterogeneity, for the description of the metal binding data over a wide range of coverage with bivalent metal ions. In a practical biosorption process, it can be expected that the coverage of the surface of adsorbents with metal ions is rather low. Then we assumed that the electrostatic effects and other nonideal behavior of adsorbate metal ions are 
negligible and simplified their model by setting the heterogeneity and nonideality parameters equal to one. Thus, the metal-binding constants, $K_{\mathrm{Mi}}$ ( $\left.\mathrm{dm}^{-3} \mathrm{~mol}\right)$, in Eq.[6] is defined as

$$
K_{\mathrm{Mi}}=\theta_{i} /\left\{\alpha_{i}\left(1-\theta_{i}\right)\left[\mathrm{M}^{2+}\right]\right\},
$$

where $\theta_{i}$ is the fraction of type $i$ sites occupied by bivalent metal ions. The number of metal ions bound to 1 dry-g of $H$. akashiwo, $X_{\mathrm{M}}$, can be expressed as the sum of the number of metal ions bound to type 1 and type 2 sites;

$$
X_{\mathrm{M}}=N_{1} \frac{K_{1} K_{\mathrm{M} 1}\left[\mathrm{M}^{2+}\right]}{K_{1} K_{\mathrm{M} 1}\left[\mathrm{M}^{2+}\right]+K_{1}+\left[\mathrm{H}^{+}\right]}+N_{2} \frac{K_{2} K_{\mathrm{M} 2}\left[\mathrm{M}^{2+}\right]}{K_{2} K_{\mathrm{M} 2}\left[\mathrm{M}^{2+}\right]+K_{2}+\left[\mathrm{H}^{+}\right]}
$$

Figures 2 and 3 show the $\mathrm{pH}$ dependence of the number of cadmium and lead ions bound to $H$. akashiwo, respectively. A preliminary kinetic experiments for the metal-alga system were conducted. The biosorption reaction proceeded rapidly and 10 minutes or so were enough to attain the equilibrium. From the results, we determined the contact time for the equilibrium experiments as 1 hour. 
A nonlinear least-squares method was applied to find two constants, $K_{\mathrm{M} 1}$ and $K_{\mathrm{M} 2}$, using Eq. [8]. The obtained constants are indicated in Table 2. The solid lines in the figures represent the theoretical curves calculated from Eq. [8] using the constants listed in Tables 1 and 2. The figures demonstrate a good agreement of the experimental data with the theoretical curves. It must be noted that the presence of counter or co-ions in the cell wall material was neglected in this model; therefore the acid-dissociation constants and the metal-binding constants listed in Tables 1 and 2 are dependent on the salt level. 


\section{SUMMARY}

Marine microalga, Heterosigma akashiwo (Hada) Hada, which is a major constituent of red tides on the coast of Japan, was applied to the recovery of cadmium and lead ions from dilute acidic solutions A simple metal-binding model was used for the description of metal binding data. The results showed that the biosorption of bivalent metal ions to $H$. akashiwo was due to monodentate binding to two different types of acidic sites: carboxylic and phosphatic-type sites. 


\section{APPENDIX A: NOMENCLATURE}

$$
\begin{aligned}
& K_{i} \quad=\text { acid dissociation constant of type } i \text { acidic sites }\left(\mathrm{mol} \mathrm{dm}^{-3}\right) \\
& K_{\mathrm{M} i}=\text { metal binding constant of type } i \text { acidic sites }\left(\mathrm{dm}^{3} \mathrm{~mol}^{-1}\right) \\
& N_{i} \quad=\text { number of type } i \text { acidic sites }\left(\mathrm{mol} \mathrm{g}^{-1}\right) \\
& X_{\mathrm{H}} \quad=\text { number of protonated acidic sites on/in H. akashiwo }\left(\mathrm{mol} \mathrm{g}^{-1}\right) \\
& \left.X_{\mathrm{M}} \quad=\text { number of metal ions bound to H. akashiwo (mol g }{ }^{-1}\right) \\
& \alpha_{i} \quad=\text { degree of dissociation of type } i \text { acidic sites (-) } \\
& \theta_{i} \quad=\text { fraction of type } i \text { acidic sites occupied by metal ions (-) }
\end{aligned}
$$




\section{REFERENCES}

1. Stone, H. C., Wilson, S. B., and Overnell, J., Comp. Biochem. Physiol, 85C, 259 (1986).

2. Viarengo, A., Moore, M. N., Mancinelli, G., Mazzucotelli, A., Pipe, R. K., and Farrar, S.V., Mar. Biol., 94, 251 (1987).

3. Plette, A. C. C., Benedetti, M. F., and van Riemsdijk, W. H., Environ. Sci. Technol. 30, 1902 (1996).

4. Seki, H., Suzuki, A., and Mitsueda, S., J. Colloid Interface Sci. 197, 185 (1998).

5. Volesky, B., and Prasetyo, I., Biotechnol. Bioeng. 43, 1010 (1994).

6. Seki, H., and Suzuki, A., J. Colloid Interface Sci. 206, 297 (1998).

7. Plette, A. C. C., van Riemsdijk, W. H., Benedetti, M. F., and van der Wal, A., J. Colloid Interface Sci. 173, 354 (1995). 


\section{Figure Captions}

FIG. 1. Number of protonated acidic sites of H. akashiwo as a function of $\mathrm{pH}$. The number of protonated acidic sites was determined by potentiometric titration for $0.3 \mathrm{dm}^{3}$ of a solution containing H. akashiwo $\left(0.1 \mathrm{~g} \mathrm{dm}^{-3}\right)$ and $\mathrm{NaNO}_{3}\left(0.1 \mathrm{~mol} \mathrm{dm}{ }^{-3}\right)$ with $0.1 \mathrm{~mol} \mathrm{dm}{ }^{-3} \mathrm{HNO}_{3}$ or $\mathrm{NaOH}$. The solid line represents the theoretical curve calculated from Eq. [5].

FIG. 2. pH dependence of cadmium biosorption to $H$. akashiwo at $30^{\circ} \mathrm{C}$. Ionic strength was adjusted to $0.1 \mathrm{~mol} \mathrm{dm}^{-3}$ by $\mathrm{NaNO}_{3}$. Concentration of $H$. akashiwo and initial concentration of $\mathrm{Cd}\left(\mathrm{NO}_{3}\right)_{2}$ are indicated in the figure. The solid lines represent the theoretical curves calculated from Eq. [8].

FIG. 3. $\mathrm{pH}$ dependence of lead biosorption to $H$. akashiwo at $30^{\circ} \mathrm{C}$. Ionic

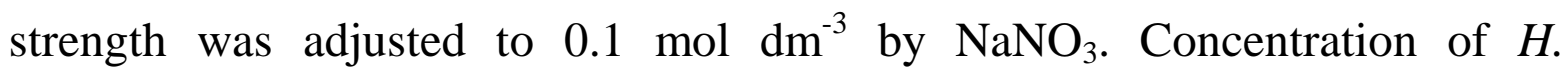
akashiwo and initial concentration of $\mathrm{Pb}\left(\mathrm{NO}_{3}\right)_{2}$ are indicated in the figure. The solid lines represent the theoretical curves calculated from Eq. [8]. 
TABLE 1

Equilibrium Parameters for Acid Dissociation

\begin{tabular}{lcl}
\hline & $\mathrm{p} K$ & $N$ \\
\hline Carboxylic & 3.90 & $1.79 \times 10^{-3}$ \\
Phosphatic & 6.64 & $0.70 \times 10^{-3}$ \\
Amino & 9.51 & $2.79 \times 10^{-3}$ \\
\hline
\end{tabular}

TABLE 2

Metal-Binding Constants, $\mathrm{p} K_{M i}$, for $\mathrm{Cd}$ and $\mathrm{Pb}$ Biosorption

\begin{tabular}{lcc}
\hline & Cadmium & Lead \\
\hline Carboxylic & -2.36 & -2.89 \\
Phosphatic & -4.47 & -5.53 \\
\hline
\end{tabular}




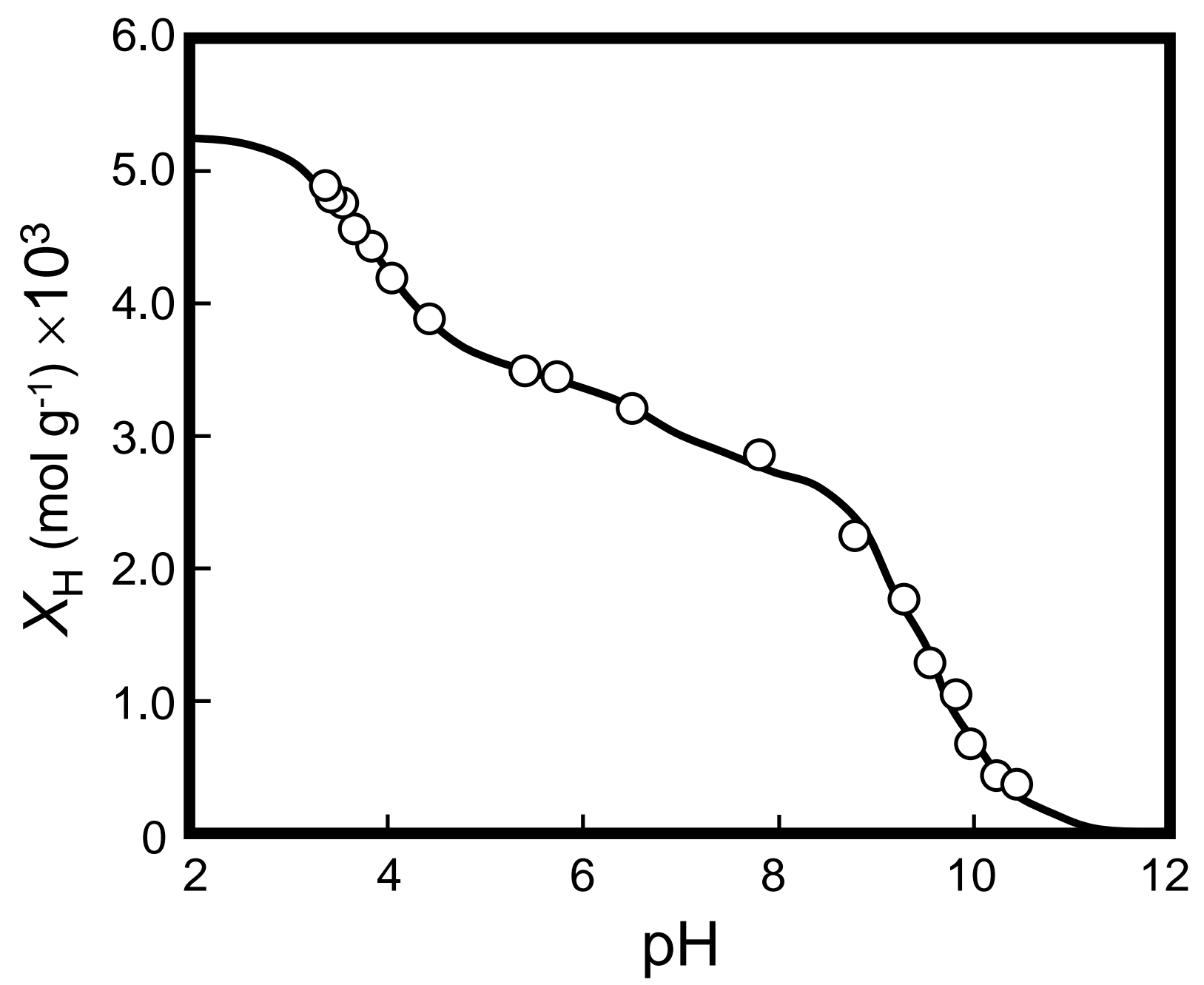




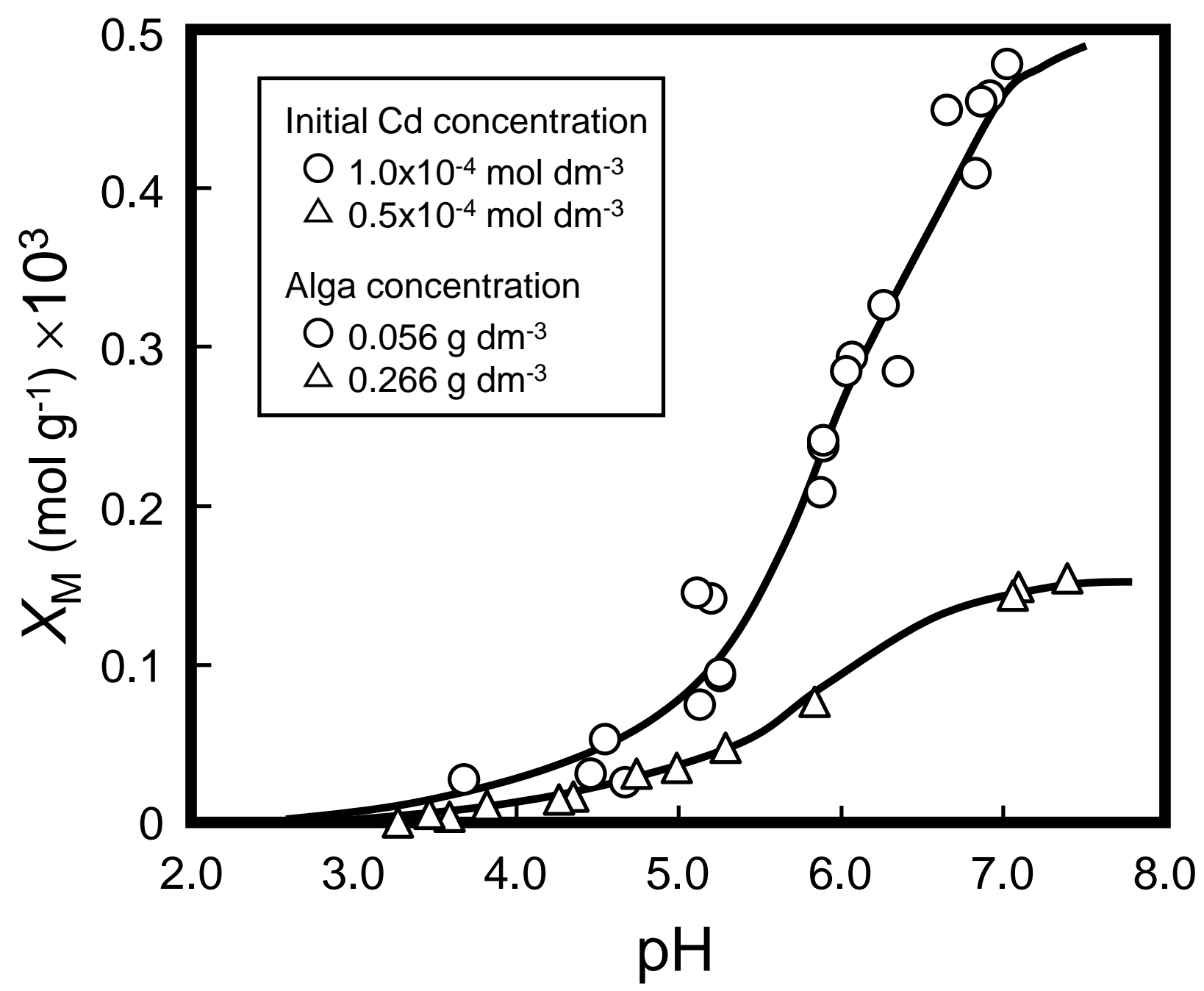




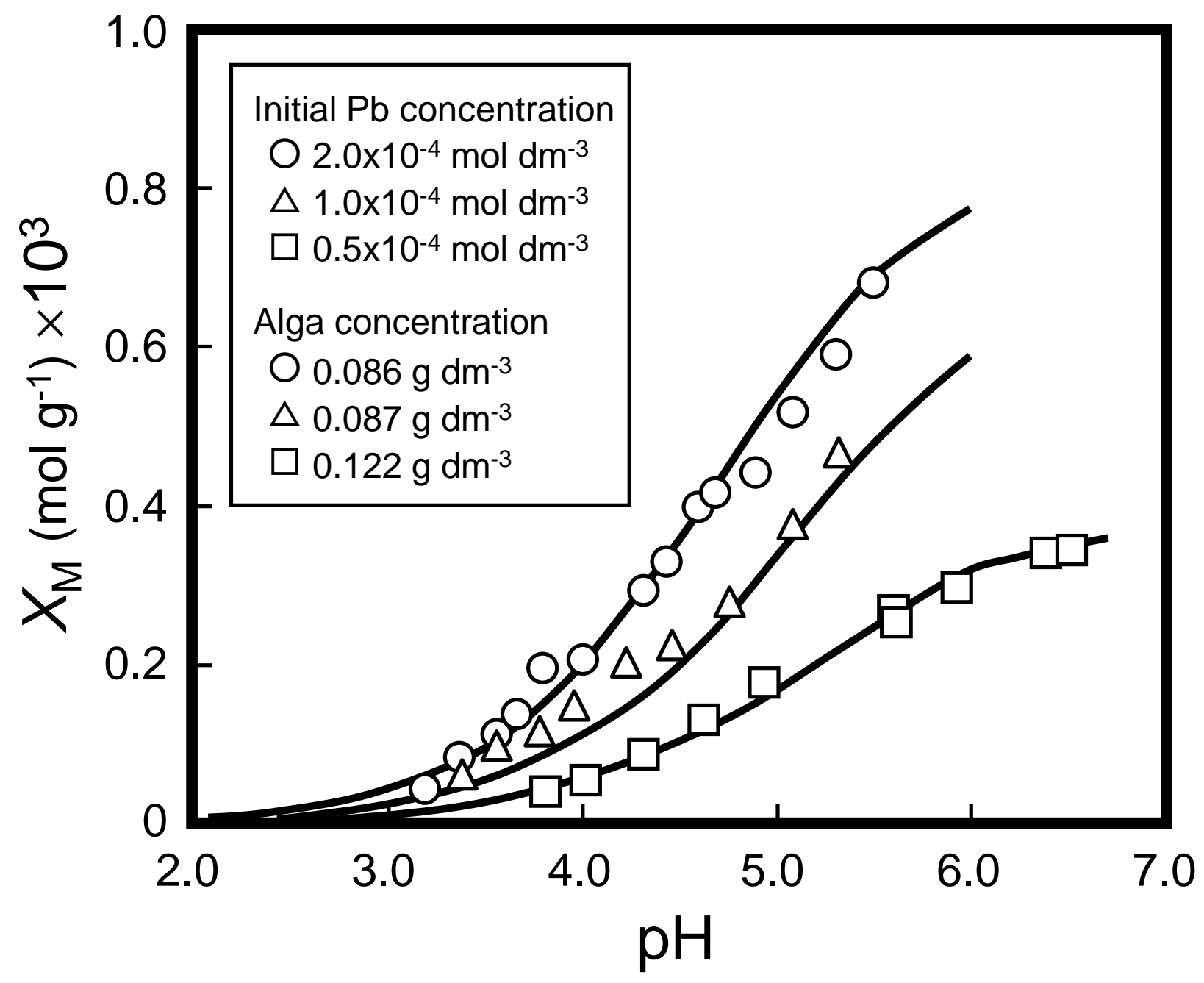

